Supplement of Hydrol. Earth Syst. Sci., 24, 4317-4337, 2020

https://doi.org/10.5194/hess-24-4317-2020-supplement

(c) Author(s) 2020. This work is distributed under

the Creative Commons Attribution 4.0 License.

(c) (1)

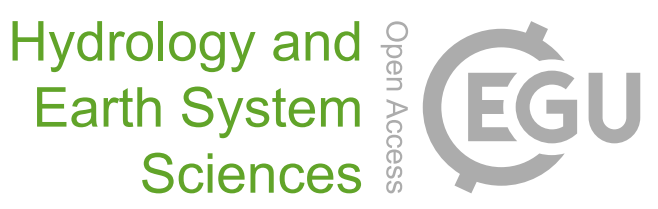

Supplement of

\title{
Climate elasticity of evapotranspiration shifts the water balance of Mediterranean climates during multi-year droughts
}

Francesco Avanzi et al.

Correspondence to: Francesco Avanzi (francesco.avanzi@ cimafoundation.org)

The copyright of individual parts of the supplement might differ from the CC BY 4.0 License. 
Table S1. Overview of all measured or estimated data, their spatial-temporal resolution, whether they were measured/estimated in situ or remotely, and their use in the paper (see the Methods section in the main text for details). SWE is Snow Water Equivalent, ET is evapotranspiration, $\Delta \mathrm{S}$ is annual change in subsurface storage.

\begin{tabular}{ccccc}
\hline Attribute & Spatial Resolution & Temporal Resolution & In situ vs. remotely sensed & Use \\
\hline Air temperature (meas.) & Point & Daily & In situ & Force PRMS and drought climatology \\
Precipitation (meas.) & Point & Daily & In situ & Force PRMS (through DRAPER) \\
Precipitation (meas.) & Point & Monthly & In situ & Drought climatology \\
Precipitation (est.) & Contours (PRISM) & Monthly & Blended & Force PRMS (through DRAPER) \\
Precipitation (est.) & $800 \mathrm{~m}$ (PRISM) & Annual & Blended & PRMS performance assessment \\
SWE (meas.) & Point (courses) & Monthly & In situ & Drought climatology \\
$E T$ (est.) & $30 \mathrm{~m}$ & Annual & Remotely sensed (derived) & PRMS performance assessment \\
$\Delta$ S (est.) & Basin-wide & Annual & Remotely sensed (derived) & PRMS performance assessment \\
Full-natural flow (est.) & Point & Daily & In situ & PRMS performance assessment \\
Full-natural flow (est.) & Point & Annual & In situ & PRMS performance assessment \\
\hline
\end{tabular}


Table S2. List of precipitation station used to compute annual statistics of precipitation across the Feather River in Figure 2 and Table 1 (main text). All data available at https://cdec.water.ca.gov/ (visited July 19, 2019).

\begin{tabular}{cccc}
\hline ID & Name & Elevation $(\mathrm{m})$ & Operator \\
\hline BCM & BRUSH CREEK (DWR-2) & 1085 & CA Dept of Water Resources \\
BCR & BRUSH CREEK RS & 1072 & US Forest Service \\
BUP & BUCKS CREEK POWERHOUSE & 536 & Pacific Gas \& Electric \\
CNY & CANYON DAM & 1390 & Pacific Gas \& Electric \\
CBO & CARIBOU PH & 910 & CA Dept Water Resources and Pacific Gas \& Electric \\
CHS & CHESTER & 1380 & US Forest Service \\
PLE & PLUMAS EUREKA PARK & 1574 & Plumas County \\
PRT & PORTOLA & 1478 & National Weather Service \\
QRD & QUINCY RADIO STATION & 1042 & National Weather Service \\
QNC & QUINCY RS (USFS) & 1042 & US Forest Service \\
SRR & SIERRAVILLE RS (USFS) & 1516 & US Forest Service \\
STV & STRAWBERRY VALLEY & 1160 & National Weather Service \\
VNT & VINTON & 1506 & National Weather Service \\
\hline
\end{tabular}


Table S3. List of snow-course stations used to compute annual statistics of Snow Water Equivalent (SWE) across the Feather River in Figure 2 and Table 1 (main text). All data available at https://cdec.water.ca.gov/ (visited July 19, 2019).

\begin{tabular}{ccc}
\hline ID & Name & Elevation $(\mathrm{m})$ \\
\hline ABY & ABBEY & 1722 \\
ANR & ANTELOPE RIDGE & 1722 \\
BCP & BROWNS CAMP & 1645 \\
CHF & CHESTER FLAT & 1402 \\
CHU & CHURCH MEADOWS & 2042 \\
ERB & EUREKA BOWL & 2072 \\
EUR & EUREKA LAKE & 1890 \\
FEM & FEATHER RIVER MEADOW & 1645 \\
FP3 & FREDONYER PASS 3 & 1783 \\
FCV & FRENCHMAN COVE & 1767 \\
GRZ & GRIZZLY RIDGE & 2103 \\
HRF & HARKNESS FLAT & 1889 \\
HS2 & HUMBUG SUMMIT 2 & 1478 \\
KTL & KETTLE ROCK & 2225 \\
LTT & LETTERBOX & 1706 \\
LLP & LOWER LASSEN PEAK & 2514 \\
MLF & MILL CREEK FLAT & 1798 \\
MDY & MOUNT DYER 1 & 2164 \\
MD2 & MOUNT DYER 2 & 1844 \\
MHG & MOUNT HOUGH & 2042 \\
MSV & MOUNT STOVER & 1706 \\
PLP & PILOT PEAK (DWR) & 2072 \\
RWL & ROWLAND CREEK & 2042 \\
3LK & THREE LAKES & 1905 \\
WRN & WARNER CREEK & 1554 \\
\hline & &
\end{tabular}


Table S4. Observed shift in precipitation-runoff relationship for the twelve main basins draining the western side of the California Sierra Nevada (in addition to the Feather River) and a representative value of annual precipitation during dry periods; see Section 2.3.1 and Equation 1 in the main text for a definition of all symbols. Contrary to Figure 4 in the main text, precipitation was estimated from PRISM maps with no daily tilting using in-situ data. The asterisk (*) denotes statistically significant values (that is, the sign of the confidence bounds agrees, 95\% confidence level).

\begin{tabular}{ccccc}
\hline Basin & $P(\mathrm{~m})$ & $Q_{\text {dry }, \mathrm{P}_{\mathrm{I}}}(\mathrm{m})$ & $Q_{\text {dry }, \mathrm{P}}(\mathrm{m})$ & $M_{Q}(\%)$ \\
\hline Yuba & 1.23 & 0.53 & 0.59 & $-10.05^{*}$ \\
American & 0.96 & 0.33 & 0.37 & $-12.48^{*}$ \\
Cosumnes & 0.78 & 0.12 & 0.15 & $-19.69^{*}$ \\
Mokelumne & 0.93 & 0.34 & 0.40 & $-14.44^{*}$ \\
Stanislaus & 0.87 & 0.29 & 0.33 & $-14.01^{*}$ \\
Tuolumne & 0.80 & 0.32 & 0.37 & $-14.41^{*}$ \\
Merced & 0.72 & 0.21 & 0.25 & $-15.10^{*}$ \\
San Joaquin & 0.68 & 0.25 & 0.31 & $-20.39^{*}$ \\
Kings & 0.68 & 0.27 & 0.32 & $-16.04^{*}$ \\
Kaweah & 0.62 & 0.17 & 0.20 & -14.89 \\
Tule & 0.49 & 0.06 & 0.07 & -21.74 \\
Kern & 0.40 & 0.07 & 0.08 & -19.67 \\
\hline
\end{tabular}




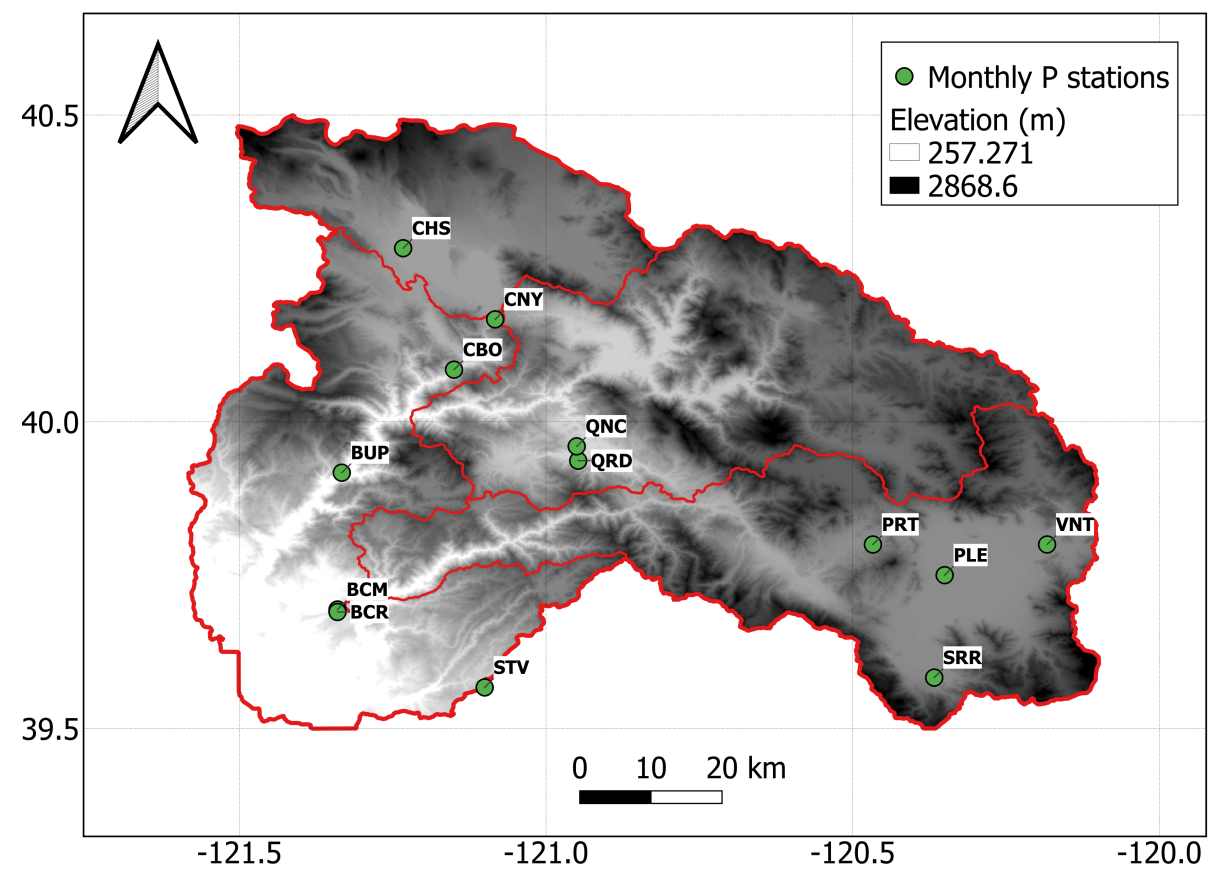

Figure S1. Precipitation station used to compute annual statistics of precipitation across the Feather River in Figure 2 and Table 1 (main text). All data available at https://cdec.water.ca.gov/ (visited July 19, 2019). 


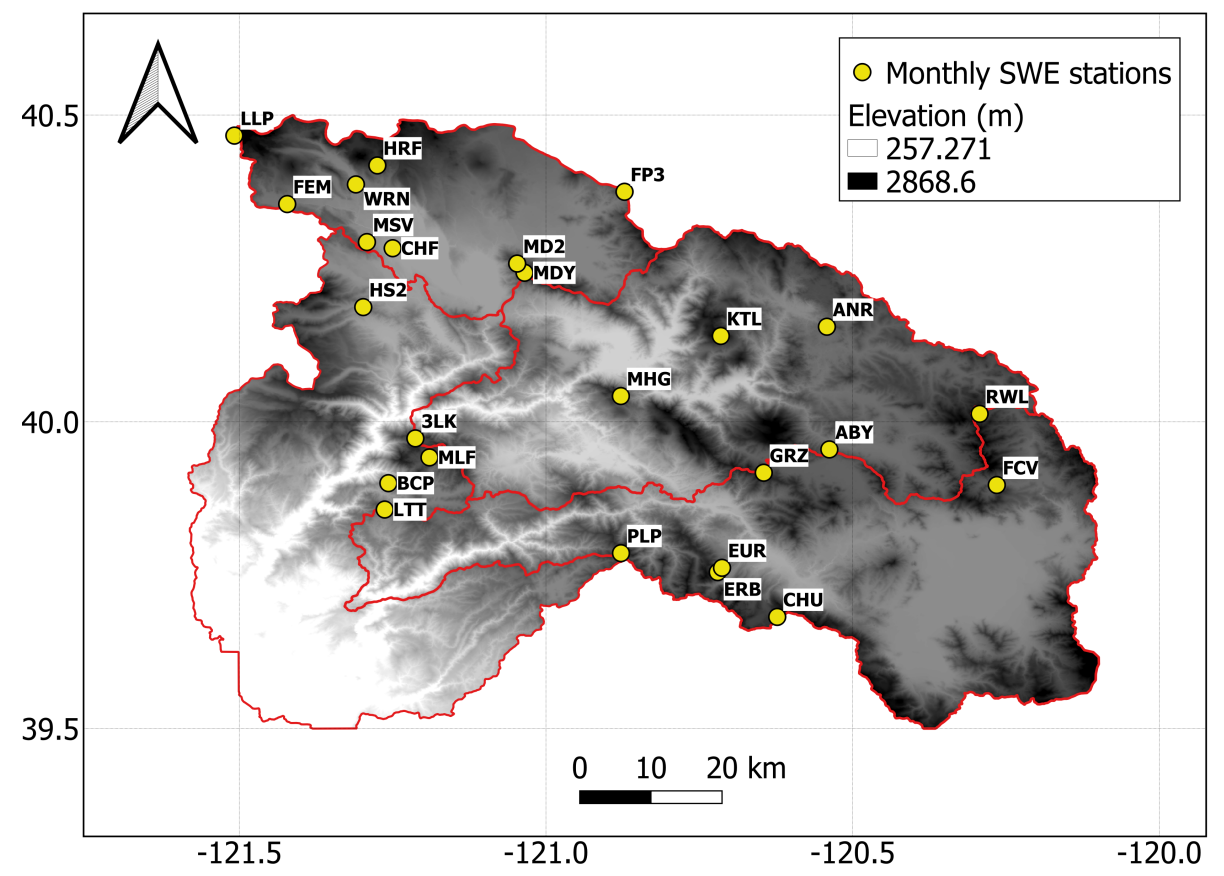

Figure S2. Snow-course stations used to compute annual statistics of Snow Water Equivalent (SWE) across the Feather River in Figure 2 and Table 1 (main text). All data available at https://cdec.water.ca.gov/ (visited July 19, 2019). 

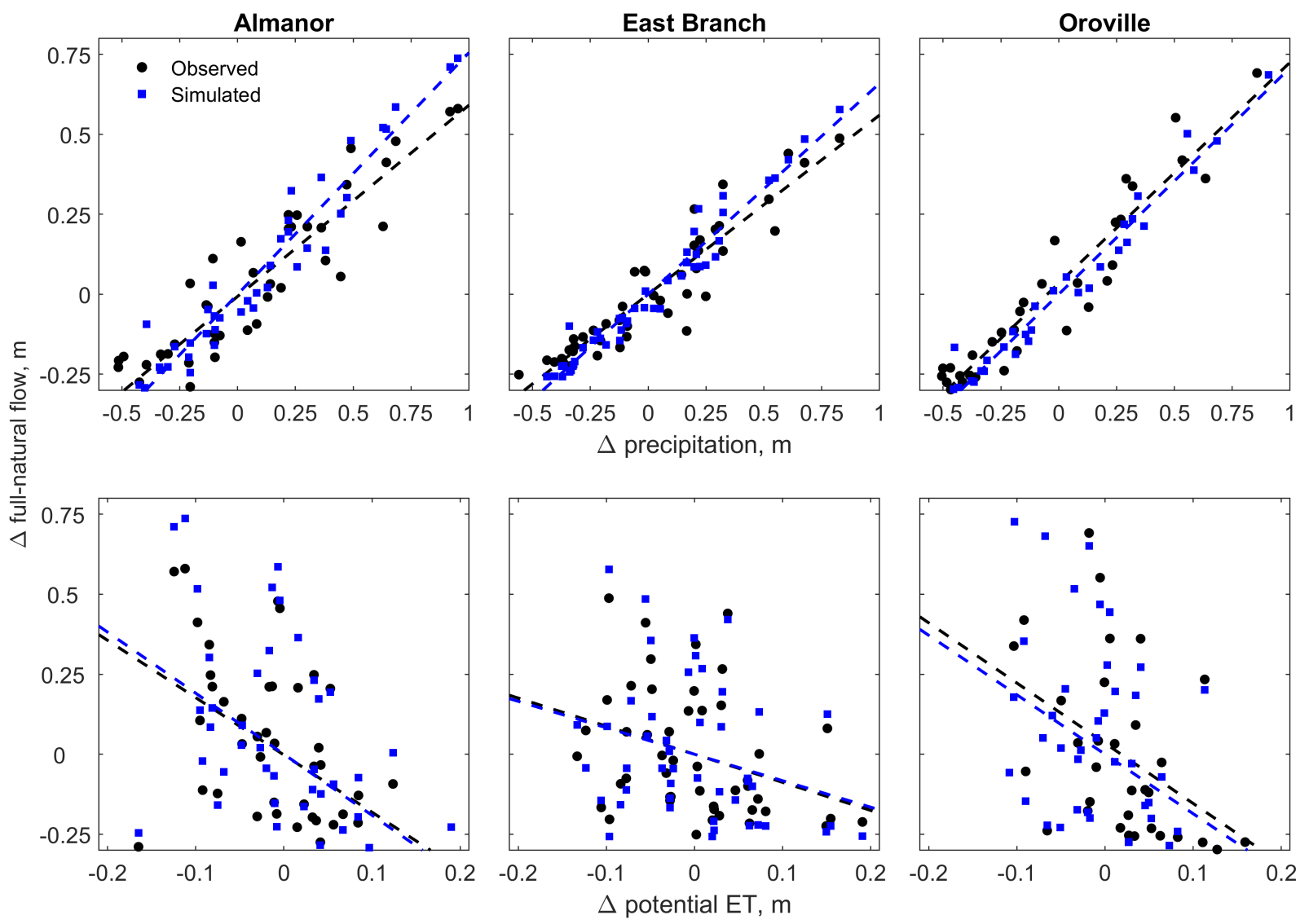

Figure S3. Modeled vs. observed univariate climate elasticity of full-natural flow to annual precipitation and potential evapotranspiration for the three basins under study with complete annual data. Precipitation, potential evapotranspiration, and full-natural flow were reported as differences $(\Delta)$ from a long-term mean across the available period of record. 

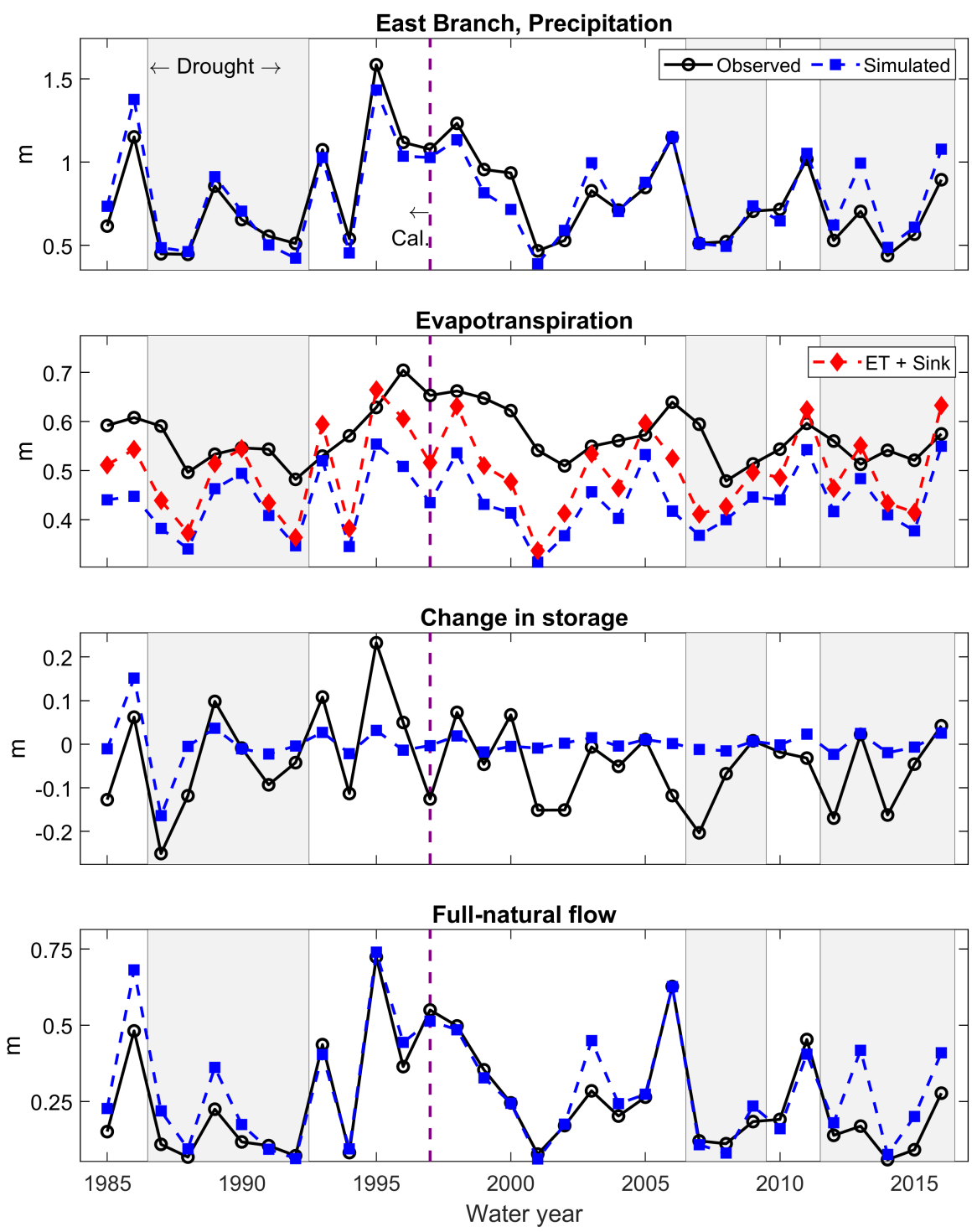

Figure S4. Simulated vs. observed (estimated) annual basin-wide water-balance components $(P, E T, \Delta S$, and $Q)$ for the East Branch sub-basin. 

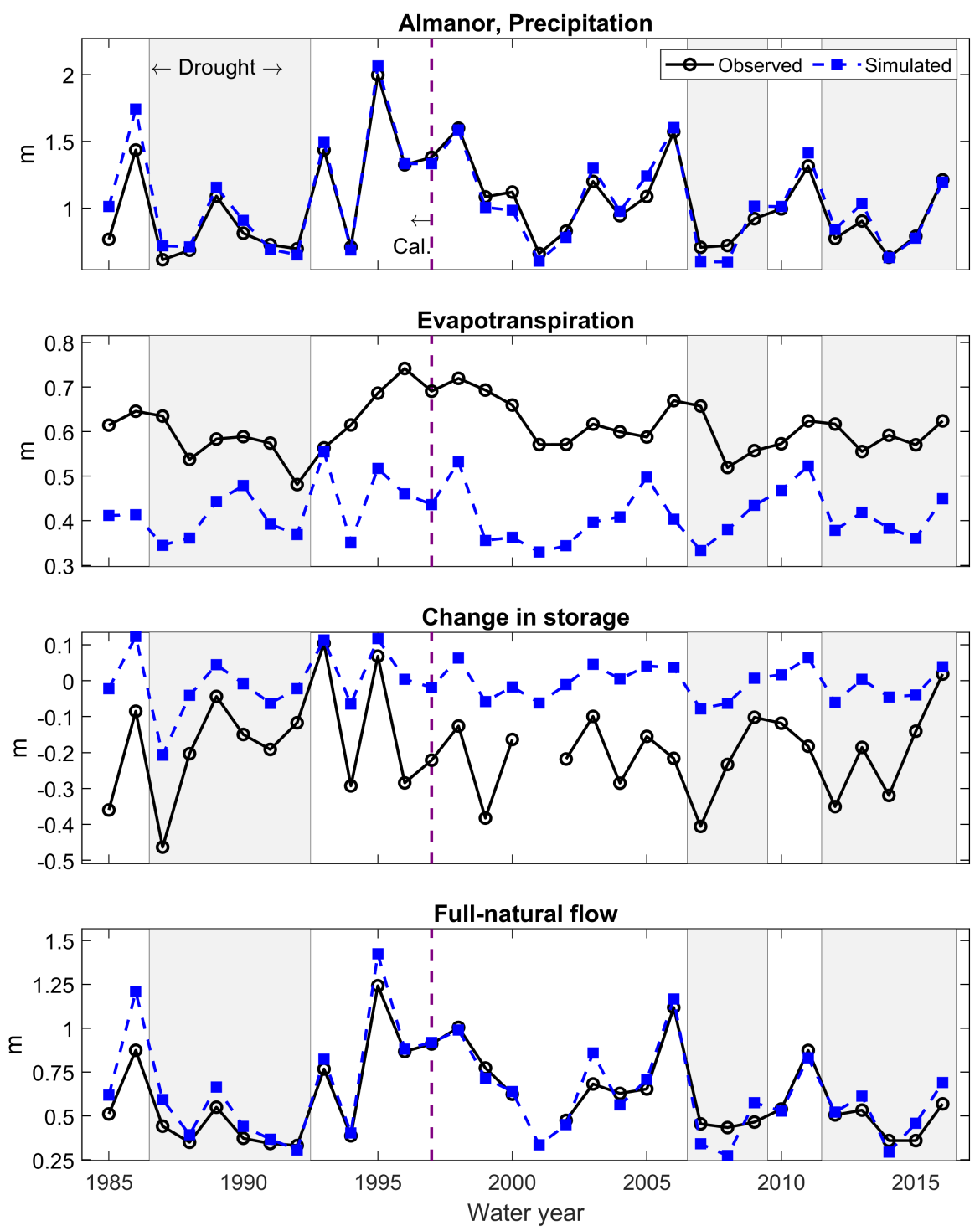

Figure S5. Simulated vs. observed (estimated) annual basin-wide water-balance components $(P, E T, \Delta S$, and $Q$ ) for the Almanor subbasin. The groundwater-sink term in this basin was set to zero during the original calibration. 

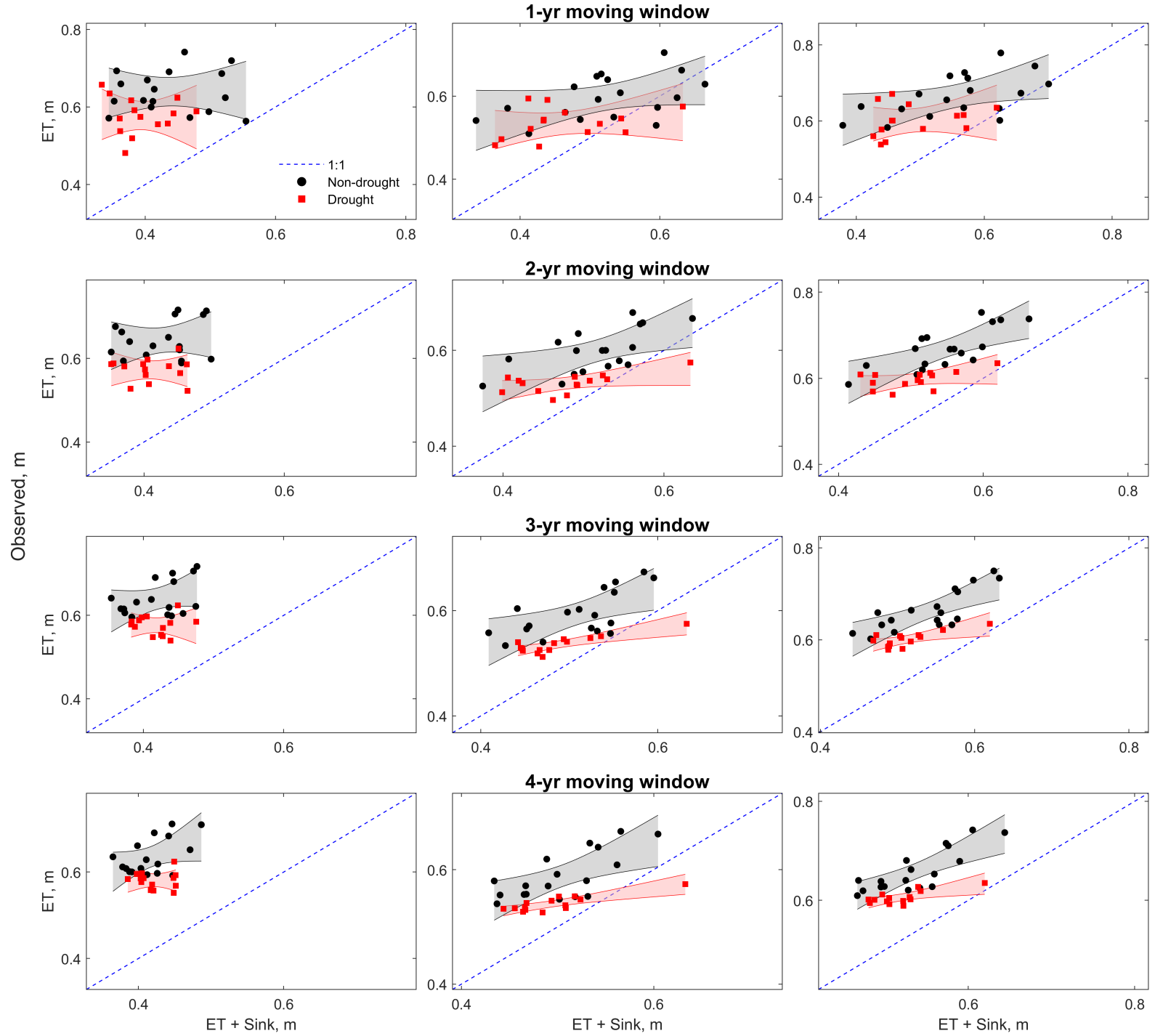

Simulated, $m$

Figure S6. Simulated vs. observed average $E T$ during drought (red) and non-drought (black) water years. Annual $E T$ values were averaged using a moving window of 1 to 4 water years and included the groundwater-sink mass-flux component. The red and grey bands represent $95 \%$ confidence intervals for the regressions. 

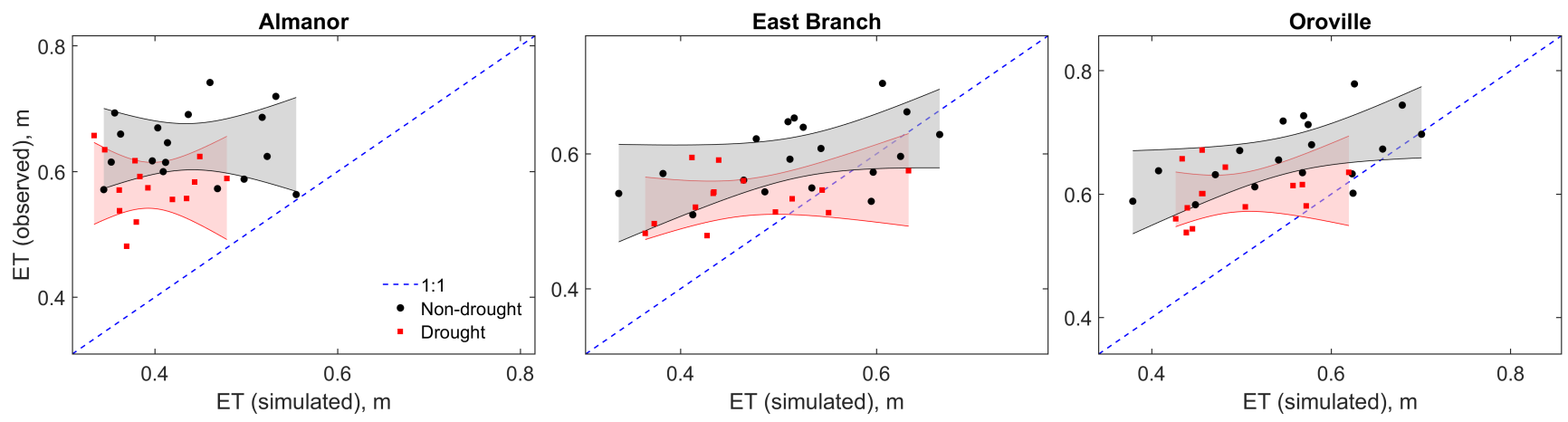

Figure S7. Simulated vs. observed annual basin-wide ET separated between drought (red) and non-drought (black) years. Contrary to Figure 8 in the main text, simulated annual ET here does not include the groundwater-sink mass-flux component. The red and grey bands represent $95 \%$ confidence intervals for the regressions. 